\title{
ESSE TAL DE FINAL FELIZ
}

Andressa Kelly Soares Mulato* Carlos Velázquez**
* andressissima@gmail.com

Graduada em Comunicação Social pela Universidade de Fortaleza, UNIFOR. Pesquisadora do Movimento Investigativo Transdisciplinar do Homem - MITHO.

**caveru@unifor.br

Pós-doutor em Filosofia da Educação, UMinho. Pós-doutor em Estudos Culturais e Membro Integrado do CLLC - FCT, ambos Universidade de .

RESUMO: O mito do herói remonta às épocas mais remotas da humanidade e reflete a batalha dos sujeitos na busca criativa por profundidade em sua integração com o real. $O$ arquétipo do herói tem sempre nos acompanhado nos mitos, nos relatos fantásticos e na literatura, entretanto, mais recentemente, sob o desenvolvimento da cultura industrial, esse arquétipo foi renovado: recebeu superpoderes e identidade secreta. Este herói-superproduto carrega atualmente o papel de messias salvador e guardião do happy end, transformando, com seus superpoderes, sua própria presença e função arquetípicas. Sob o auspício da metodologia de pesquisa no, com recurso a un conjunto bibliográfico e documental de ordem multidisciplinar, analisamos essa transformação a fim de fundamentar nossas especulações sobre suas possíveis consequências. Concluímos que a Indústria Cultural usa a imagem do herói para promover seus ideais, a despeito dos comprometimentos individuais e coletivos que outrora o herói ensejava.

PALAVRAS-CHAVE: Mitologia; Super-Herói; Indústria Cultural Quadrinhos.
RÉSUMÉ: Le mythe du héros remonte aux époques les plus reculées de l'humanité et reflète la bataille des sujets dans la recherche créative par profondeur en leur intégration dans le réel. L'archétype du héros a toujours été présent dans les mythes, les histoires fantastiques et la littérature, cependant, plus récemment, au titre du développement de la culture industrielle, cet archétype a été rénové: il a reçu super-pouvoirs et une identité secrète. Ce héros-super-produit personnifie le rôle du Messie Sauveur et gardien du happy end, tout en transformant, avec ses superpuissances, sa propre présence et fonction archétypiques. Sous les auspices de (a) the recherche qualitative du paradigme jungienne, sur un ensemble bibliographique et documentaire d'ordre multidisciplinaire, nous analysons cette transformation afin de fonde nos spéculations sur ses conséquences éventuelles. On conclu que l'industrie culturelle s'utillise des super-héros dans le but de disseminer leurs ideaux, en détriment des compromis individuels et collectifs que auparavant l'héro suposait.

MOTS-CLE: Mythologie; Super-Héros; Industrie Culturelle; Band dessinée. 


\section{INTRODUÇÃO}

É comum ouvirmos falar de heróis muito cedo em nossas vidas. Essa figura fantástica costuma habitar o imaginário de nossa infância e é através dela que descobrimos um universo de aventuras, de virtudes e um caminho para o final feliz. Os contos de fadas, as histórias em quadrinhos, os desenhos da TV e as produções do cinema são os meios mais comuns para que esses personagens invadam nosso cotidiano e nos mostrem que existe algo além de nós mesmos que é capaz de transformar uma simples narrativa em algo fantástico e inspirador.

Se pararmos para refletir, os heróis sempre estiveram por aqui. De Hércules a Superman, é possível notar que o homem tem mantido, através do tempo e das transformações sociais, figura do herói como um amigo que o acompanha. Se refletirmos com um pouco mais de afinco, é possível notar também que, de Hércules a Superman, o herói vem sofrendo uma série de transformações. A princípio, pode não parecer nada demais, que importância pode ter se ele usa a pele de um leão ou a cueca por cima da calça? Um herói é um herói. No entanto, a pergunta permanece: será que se trata do mesmo herói?

Este trabalho procura comparar o herói tradicional mítico e o super-herói, próprio da sociedade industrial, com intuito de compreender o papel desses heróis na sociedade delinear suas diferenças. Contrapomos, para o efeito, a carga arquetípica do herói mítico perante estruturas contextuais e formais em narrativas de super-heróis contemporâneos, assim, em perspectiva transdisciplinar, com auxílio de fontes bibliográficas e documentais, induzimos a hipótese de que a Indústria Cultural usa a imagem do herói para promover seus ideais, a despeito dos comprometimentos individuais e coletivos que outrora o herói ensejava.

\section{A MITOLOGIA DA FELICIDADE}

Em 1955, foram pela primeira vez publicadas as observações de Walter Benjamin sobre um processo de intermitência histórica que, no entanto, intensificava-se na era industrial. Não era novidade, na época, falar sobre reprodução de obras de arte: um músico executa várias vezes suas composições ou as de outrem; um dramaturgo representa várias vezes suas obras, como um poeta ou uma dançarina reproduzem inúmeras vezes suas performances, que podem incluir ou constituir-se de obras de terceiros. No caso das artes gráficas ou plásticas, os ateliês constituíam verdadeiras oficinas de produções e reproduções, muitas vezes orientadas por interesses lucrativos. O que há de novo no ensaio de Benjamin é a diferenciação de reprodutibilidade de obras de arte por meios tecnológicos sofisticados, cuja intensificação alude não apenas ao número de cópias, mas também, em relação inversamente proporcional, à dispensa do protagonismo do autor e dos fruidores da cópia. Por outras palavras, não é a mesma coisa empenhar-se na aventura técnica de 
copiar a lápis uma gravura de Goya e apertar um botão para fotografá-la. No primeiro caso, a pessoa que faz a cópia está implicada e, em função dessa implicância, as cópias são limitadas; no segundo caso, o comprometimento técnico do autor da cópia é mínimo, pois o trabalho descansa, cada vez mais, nos recursos do aparelho; não obstante, as cópias são praticamente ilimitadas, embora, em função de sua abundância e facilidade, o relacionamento das pessoas com essas cópias tenda à futilidade. Na visão de Benjamin, esses meios de reprodutibilidade facilitam o acesso às obras, embora o preço desse acesso seja alto, pois incide diretamente sobre a desvalorização da experiência, do aqui e agora ou, melhor, da aura da obra experiencial.

Esse fenômeno acabaria por facilitar o surgimento de uma cultura acostumada a receber experiências assim reproduzidas e, portanto, limitadas por sua mediação tecnológica, em que o papel do receptor estaria quase limitado à assimilação passiva de experiências deslocadas em tempo e lugar, aquis e agoras retirados de seus contextos e sem possibilidade de ajuste, em tempo real, com seus novos contextos de execução e fruição. Eis, pois, a gênese de uma nova cultura que Benjamin denominou como Cultura de Massa. No encalço deste autor, Theodor Adorno e Max Horkheimer, articulando a caracterização da cultura de massa com o estudo minucioso de seus meios e formas de produção e propagação e, sobretudo, com a crítica aos efeitos sociais que identificavam nesse aglomerado, desenvolveram o conceito de Indústria Cultural. Vale dizer que o que mais preocupava esses críticos era que o conjunto formado por meios de comunicação como televisão, rádio, jornais, revistas e cinema, por ser mais acessível às massas, ao corpo social, facilitava - e ainda facilita - a propagação de ideologias, ao ponto de exercer certo controle social orientado aos interesses políticos e econômicos convenientes às elites detentoras desses meios.

O jornal, as revistas, o rádio, o cinema, a TV e, não muito tempo depois, a Internet deram espaço para um seguimento completamente novo de gerar conteúdo e transmiti-lo para o maior número possível de pessoas. Esses meios de comunicação trouxeram com o seu advento a realização de algo que parecia impossível para o homem: estar em vários lugares ao mesmo tempo. O desenvolvimento da produção cultural e a ascensão de suas muitas formas de reprodução deram vazão ao questionamento dos autores alemães com relação à profundidade dessa cultura e do sistema que a propaga. Os produtos culturais se estabelecem de forma escancarada como um produto industrial, uma mercadoria, e o movimento global de cultura como um mercado. Como diz Baudrillard, a cultura passou a integrar o centro comercial e, ao mesmo tempo, a mercadoria culturalizou-se também "[...] porque surge transformada em substância lúdica e distintiva, em acessório de luxo, em elemento no meio de outros elementos da panóplia geral dos bens de consumo". ${ }^{1}$
BAUDRILLARD. $A$ sociedade de consumo, p. 18. 
2. ADORNO; HORKHEIMER. Dialética do Esclarecimento.

3. ECO. Apocalípticos e integrados.

4. BAUDRILLARD. $A$ sociedade de consumo, p. 15.
Apesar das duras críticas feitas por Adorno e Horkheimer, ${ }^{2}$ sabemos que há duas formas de pensar a Indústria Cultural: a apocalíptica e integrada. Umberto Eco chamou de integrados aos entusiastas da Indústria Cultural. ${ }^{3}$ Esses viam nela a oportunidade de integrar-se mais facilmente no meio em que se vive, de identificar-se com seus semelhantes celebrando a globalização da cultura. Entretanto, os apocalípticos veem na indústria uma função quase que totalitarista, a qual promove, acima de tudo, a alienação das massas. É claro, a definição do capitalismo como forma hegemônica de modelo econômico transformou a vida do homem em diversos aspectos, e dessa maneira não podemos negar o surgimento de um modelo de vida que organiza as atividades humanas em torno do capital. Tudo é condicionado à economia, até mesmo a cultura. Mas também é inegável que essa mesma indústria, acusada de aprisionar e influenciar mentes, possui, em seu contexto, um papel transformador que acaba por transcender à dinâmica mercadológica.

O conceito de Indústria Cultural, desde sua formulação tem passado por mudanças e ainda é objeto importante de estudo. A transformação fundamental diz respeito justamente ao nascimento da sociedade de consumo, onde a reificação se torna uma realidade. Vivemos o tempo dos objetos: existimos segundo o seu ritmo e em conformidade com sua sucessão permanente. ${ }^{4}$
O mundo pós-guerra foi o cenário dessas transformações. De um lado, havia a Europa, palco principal dos acontecimentos, e que se encontrava em maus bocados após os conflitos. Do outro lado, os Estados Unidos comemoravam não somente o fim da guerra, mas a vitória dos norte-americanos. O novo mundo era o lugar mais atraente do globo, fazia-se questão de falar sobre o sonho americano, e o american way of life virou objetivo máximo. Isso, é claro, influenciou fortemente a competitividade no mercado e o encantamento com o sonho americano virou quase uma condição para, economicamente falando, alcançar o topo. A nova meta era ganhar dinheiro para poder consumir a maior quantidade possível de produtos de arte e de cultura. Podemos observar, nesse contexto, o nascimento de um conceito de felicidade diretamente atrelado ao hábito de consumir, em que o sujeito só seria capaz de viver plenamente a realização dos seus desejos e aspirações através da prática do consumo.

\section{O CONSUMO DO DISCURSO MÍTICO E DO HEROÍSMO}

Com a industrialização da sociedade moderna, o mundo presenciou a desmistificação de símbolos em muitos aspectos da vida humana, na qual a razão tomou o primeiro lugar como ordenadora de sentido e substituta de um discurso religioso que havia controlado as direções do homem por muitos anos. É importante lembrar que o homem não perdeu sua religiosidade ou crenças por completo; esses símbolos continuam a 
5. JUNG et al. O homem e seus símbolos.

6. JUNG. Tipos Psicológicos, p. 398 400.

7. JUNG; KERÉNYI. A Criança Divina, p. 16. fazer parte de sua psique e constituem elementos importantes para a formação do sujeito. De maneira geral, esses símbolos e mitos, estes últimos entendidos como narrativas carregadas de dimensões qualitativas e compensatórias da psique, foram reconstruídos e reinstituídos com o decorrer do tempo, quando passaram a não mais fazer sentido na realidade vigente. ${ }^{5}$ Essa ressignificação, é claro, ocorreu na esfera psicológica e culminou em mudanças não apenas do contexto social, mas de características mais profundas da vida do sujeito. Ao dizer de Jung, o aparelho psíquico é autorregulatório e, face à unilateralidade causada pela atitude consciente, procura, de forma inconsciente, compensar seu equilíbrio, entregando à consciência os conteúdos constelados cujo conhecimento seria indispensável para sua readaptação. ${ }^{6}$ Todavia, esses conteúdos são deformados pela consciência e precisam, portanto, ser identificados na imaginação, na fantasia, nos sonhos ou na mitologia; igualmente, precisam ser interpretados a fim de que a consciência possa assimilá-los e seja, portanto, instigada a reconsiderar suas atitudes. Destarte, como diz Karl Kerényi, o mito é "[...] algo concreto, convertido em objeto que fala por si mesmo, que não justificamos pela interpretação e explicação, mas, em primeira linha, pelo fato de o colocarmos ali e permitirmos que expresse seu próprio sentido.”.7

$\mathrm{Na}$ sociedade moderna, em que a cultura de massa propaga um discurso de consumo colocando objetos e produtos dentro de um conceito mágico de felicidade, o discurso toma ares de mitologia, o produto usurpa o símbolo, e a carga real de significado, que deveria dar conta das várias dimensões do homem moderno, desaparece asfixiado numa enxurrada de valores descartáveis.

Eliade $^{8}$ valoriza os ensinamentos míticos e a imitação da obra dos deuses como fundamento para a formação do homem. O mito do herói simboliza psicologicamente o caminho da autorrealização e da vida criativa. É o caminho da mudança que, através da morte, leva a uma nova vida. ${ }^{9}$ É o arquétipo do herói o que representa, em sua forma mais pura, a luta humana de se desvencilhar das dificuldades diárias da existência e encontrar formas criativas de lidar com a própria vida. Podemos perceber em vários mitos, de muitas regiões do mundo, que os heróis em questão são homens que simbolizam um ideal de justiça e coragem, uma inspiração para todos aqueles que os conhecem. O herói mitológico constitui, assim, parte importante da alma humana, representando uma força de crescimento individual e social que é comum a todos. "Ele representa características fundamentais de que precisamos para o domínio da vida e o embate criativo com a nossa existência. Seu caminho é o caminho da autorrealização" ${ }^{10}$

Porém, à medida que a sociedade evolui para uma organização mais elaborada, científica, racional e altamente mecanicista, mitos e arquétipos são naturalmente recolocados para atender ao contexto social. Presenciamos mudanças
8. ELIADE. O sagrado e o profano.

9. MULLER. O Herói: Todos nascemos para ser heróis, p. 5
EM TESE
BELO HORIZONTE
v. 22
N. 2 MAIO-AGO. 2016
MULATO; VELÁZQUEZ. Esse tal de final feliz
P. $175-186$

10. MULLER. O Herói: Todos nascemos para ser heróis, $\mathrm{p}$. 05-06. 
11. MORRISON. Superdeuses, $\mathrm{p}$. 19-20. radicais na cultura como um todo. As formas de trabalho, de lazer e de pensar são fortemente influenciadas por forças que apontam para o crescimento e ascensão de um sistema cultural que engloba a todos e os anula ao mesmo tempo. $\mathrm{O}$ mito do herói nunca desapareceu, mas no decorrer da história vem sofrendo transformações que o emancipam do meio, o qual não mais fornece as respostas espirituais que o heró procura. Embora nos seja impossível precisar uma data, podemos afirmar que, por volta de 1938, quando da aparição do primeiro super-herói da indústria cultural, o produto dessa transformação heroica finalmente cobrou uma forma reconhecível e tornou-se febre nos anos seguintes.

Em 1938, logo após a queda de Wall Street causar a depressão mundial de 1929, às portas de uma segunda guerra mundial, o mundo não parecia um lugar amistoso. Homens, mulheres e crianças eram massacrados com horários absurdos de trabalho e não parecia haver uma luz no fim do túnel, até que um símbolo surgiu nas páginas sujas dos comic books.

Essa é a história da fundação de uma nova crença e de como ela conquistou o mundo. Com um relâmpago, a centelha de inspiração divina botou fogo no papel-jornal e o super-heró nasceu numa explosão de ação e cor. [...] Eles vieram nos salvar do abismo existencial, mas primeiro teriam que abrir o caminho para chegar ao nosso imaginário coletivo. ${ }^{11}$
Vindo de outro planeta, Superman só lembra os meros mortais em aparência. O homem de aço podia erguer pesos extraordinários, correr mais rápido que um trem, transpor prédios de muitos andares, dentre outros super da categoria. Em resumo, ele era tudo aquilo que não poderíamos ser, mas o grande trunfo do alienígena órfão e poderoso era, na verdade, o homem por trás do "S". Alguém com um emprego, um chefe e problemas com as garotas.

Clark Kent era um nerd, quatro-olhos, meio covarde, e sombra pacata do confiante Homem de Aço. Temos aqui o primeiro indício de que tudo mudou. Ao comparar Superman com heróis mitológicos, a diferença é clara. Teseu e Hércules eram heróis do momento em que levantavam da cama até a hora de dormir, Superman era secretamente outra pessoa.

Superman deixava claro o seu posicionamento: era um herói do povo. O Superman original era uma reação humanista e audaciosa aos temores da Grande Depressão, do avanço científico desregrado e da industrialização sem alma. [...] Não é de surpreender que tenha sido um sucesso entre a classe oprimida. Ele era decididamente lowbrow, a favor dos pobres, como qualquer salvador nascido num estábulo. ${ }^{12}$
EM TESE
BELO HORIZONTE 
13. ECO. Apocalípticos e integrados, p. 239. identificação do objeto com uma soma de finalidades nem sempre racionalizáveis, projeção na imagem de tendências, aspirações e temores particularmente emergentes num in divíduo, numa comunidade, em toda uma época histórica”. ${ }^{13}$ Os super-heróis representariam, dentro dessa perspectiva, os anseios do leitor médio, o indivíduo comum que almeja um dia ter os seus sonhos realizados. No cotidiano, Clark Kent; nos sonhos, Superman. Clark foi o elemento que justificou e transcendeu a existência do Super-Homem. Ele o fez perdurar, e através dele foi criada a maior fonte de identificação com o leitor incompreendido. Cada nova revelação a seu respeito oferecia à mídia uma inovação em personagens que poderia chamar de sua, e o conceito do super-herói capturou o público facilmente. Assim nascia o primeiro super-herói da indústria e os quadrinhos nunca mais foram os mesmos.

\section{DO CONTEXTO AO HERÓI}

Dentre os vários fenômenos culturais provocados pelos meios de comunicação no mundo contemporâneo, há o processo de mitificação dos personagens produzidos por essa indústria. O nascimento de Superman foi também o nascimento de todo um seguimento baseado na ideia de que um ser supremo e todo poderoso caminha entre nós, sempre à espreita de nossos problemas, pronto para entrar em ação quando for necessário.
O uso da superforça para defender os mais fracos e oprimidos, a identidade secreta e a luta para permanecer em um mundo opressor onde ameaças surgiam de todos os lados viraram a fórmula perfeita para chamar a atenção do leitor que vivia em condições reais não muito acolhedoras. Corroborando a ideia de que o herói se adapta ao contexto em que está inserido ou, em outras palavras, de que o super-herói responde sempre a um chamado desesperado, em 1941 Superman começou a representar uma proposta bem diferente daquela em que fora criado. Em tempos de guerra, patriotas eram heróis, e assim o herói supremo tornou-se um superpatriota. ${ }^{14} \mathrm{O}$ homem que veio do espaço agora representava - inclusive em suas cores - o Bom Americano O defensor da América, que antes atirava maridos espancadores pelas janelas, parava trens em movimento e combatia políticos corruptos, agora era um baluarte da moral e força de seu país. Claramente não poderia haver políticos corruptos ou sistema disfuncional no país que acabaria com a guerra.

Também em 1941, surgiu um super-herói criado especificamente para renovar o espírito norte-americano em período de conflito. Capitão América, o maior dos super-heróis patriotas, também possuía um nome por trás do título de "super". Como predizia o contexto da época, assim como muitos norte-americanos, Capitão América só queria dar 
uma surra em Hitler e o fez em muitas das edições de seus quadrinhos. Os anseios e esperanças de uma sociedade sempre foram reproduzidos nas artes vigentes, e com as histórias em quadrinhos não foi diferente.

Capitão América representava o ideal norte-americano, a imagem que os Estados Unidos queriam mostrar ao mundo o protetor que as nações precisavam naquele momento de incertezas. Seu papel de propaganda antinazista era tamanho que, com o fim da Guerra, suas revistas saíram de circulação. Isso serve para reforçar a ideia de que as HQs, assim como outros instrumentos da cultura de massa, são pautadas pelo contexto social, ao passo que também o transformam. Nessa conjuntura, explicita-se o caráter político das histórias em quadrinhos e como o seu meio começa a ser permeado por uma função propagandística.

Com o fim da Segunda Guerra e o início da guerra fria super-heróis começaram a enfrentar maus bocados perante o público; superpoderes não eram bem-vindos quando poderiam indicar a iminência de uma devastação nuclear. Mas, como os super-heróis refletem os ânimos de sua época, não demorou até que estes virassem cientistas ou vice-versa.

Durante a Segunda Guerra Mundial, o conceito do super-herói se espalhou como chamas num incêndio, mas então morreu tão rápida e misteriosamente quanto havia começado. O interesse do público caiu pronunciadamente após 1945, e os títulos de super-heróis desapareceram para serem substituídos por outros gêneros que triplicaram as vendas totais do mercado de quadrinhos entre 1945 e 1954. [...] O fim da guerra levou os americanos a uma era de prosperidade e paranoia. ${ }^{15}$

Em um mundo onde o status psicológico do sujeito era martirizado pela ameaça silenciosa da destruição atômica (Guerra Fria), escritores e desenhistas de histórias em quadrinhos transformaram a força do medo em esperança. A radiação, que antes era a fonte da destruição da raça humana, se transformou na fonte de poder dos transmutados super-heróis da era moderna. A corrida armamentista dividia pista com a corrida tecnológica e, como importante veículo de expressão social, os quadrinhos também carregaram a sua parcela de ficção científica e aventuras espaciais.

O conceito básico do super-herói nascido com Superman foi sofrendo mutações ao longo das décadas, de modo que pudesse assumir as características sociais, culturais e humanas de cada época e adquirir assim características da cultura de massa ao tentar abranger o maior número de pessoas possível através da identificação cultural. O processo de identificação é importantíssimo, pois é através dele que o sujeito passa a estabelecer uma relação entre o mundo em questão e o seu próprio e, por meio dessa ponte, passa a considerar 
fatores existentes nessas duas realidades. Dessa maneira é possível perceber a necessidade da criação de mitos que não mais explicam, mas na verdade amenizam os sintomas de crise gerados pela realidade social em que estão inseridos.

A cultura, através da indústria, começa então a fornecer o apoio imaginário à vida prática e, da mesma forma, esta fornece pontos de apoio prático à vida imaginária, tendo em vista que alimenta tanto o real quanto o imaginário. Sendo assim, é a cultura de massa que acaba por desenvolver a mitologia do homem moderno.

\section{QUE MITO É ESSE?}

Em uma sociedade científica que tende a tornar-se cada vez mais cética com relação a religiões e crenças, é o discurso do consumo que pretende dar conta das crises existenciais do sujeito, usando a indústria e a cultura de massa como agentes desse processo. Mitos e símbolos são recriados através desse discurso que prega a supervalorização de objetos, estabelece a ligação de ter com ser e cria um ideal de felicidade baseado na premissa do trabalho duro e do consumo. Nos moldes da indústria cultural, o termo mito costuma assumir papel um pouco diferente daquele que conhecemos quando estudamos de fato a mitologia. Em seu discurso, quando enfatiza o mito heroico, a indústria geralmente o faz de duas maneiras: como o relato de um indivíduo que, devido ao valor de sua obra, extrapolou os espaços do seu universo de atuação; ou como uma farsa, algo que a ciência demonstrará não possuir fundamento.

Edgar Morin desenvolveu um estudo sobre a indústria cultural e o processo de identificação gerado através de seus modelos, aos quais ele chama "Olimpianos Modernos". Esses personagens, em comparação com os deuses clássicos da cultura grega que habitavam o Monte Olimpo, seriam as novas fontes de adoração e inspiração geradas no âmago da sociedade industrial.

No encontro do ímpeto do imaginário para o real, e do real para o imaginário, situam-se as vedetes da grande imprensa, os olimpianos modernos. Esses olimpianos não são apenas astros de cinema, mas também os campeões, príncipes, reis e playboys, exploradores, artistas célebres [...]. ${ }^{16}$

O autor destaca que a sociedade da informação transforma essas personagens nas vedetes da atualidade. Já foram figuras endeusadas, mas agora lhes cabe assumir um papel mais humano que permita a identificação com o público. Dessa forma, a indústria - mesmo que não o pretenda - acaba por gerar mitos efêmeros, transformando em semideuses alguns indivíduos que chamam a atenção da mídia por algum motivo.
16. MORIN Cultura de massas no século XX: neurose, p. 105. 
17. MORIN. Cultura de massas no século XX: neurose.

18. MORIN. Cultura de massas no século $X X$ : neurose, p. 71
Não seria exagero, portanto, situar os super-heróis nesse mesmo olimpo. Ao assumir o papel de herói, mas também de humano comum, esses sujeitos que se colocam ao dispor da humanidade para solucionar suas maiores questões estão se colocando também em pé de igualdade com todos aqueles que consomem as suas histórias em busca de um escape da realidade tediosa. $\mathrm{O}$ desfecho de suas tramas, que geralmente emplacam o triunfo do bem sobre o mal, é o propósito da sua existência e dá ao espectador a catarse pela qual ansiava. É a recompensa que torna a vida suportável.

Através da promessa de felicidade, o discurso da cultura de massa transforma os objetos de consumo em novos talismãs e totens, ao permeá-los com uma sacralidade rasa, porém eficiente. É o que Morin, chama de uma "mitologia euforizante" ${ }^{17}$ fundamentada na ideia de felicidade como religião, mediante ideais de aventuras heroicas, proezas e amores empíricos passíveis de serem atingidos no plano material por meio de objetos de consumo.

Isso significa dizer que, de acordo com o discurso do consumo, tem-se a negação do sofrimento, a negação da culpa e, por conseguinte, a negação do espaço do outro, um recalque às mitologias e ao modo "aberto" de viver o mundo. [...] Toda crise existencial põe em questão, ao mesmo tempo, a realidade do mundo e a presença do homem no mundo. ${ }^{18}$
Tais mitos criados pela indústria cultural e reafirmados através da propaganda são privados dos valores fundamentais que proporcionam a transformação do sujeito dentro das situações impostas socialmente. A mitologia do homem moderno está revestida de uma simbolização que não é completa, portanto não exerce no campo psicológico o seu papel transformador edificante. Essa mitologia, ao invés de iniciar o sujeito em sua luta pela conquista de uma emancipação psicológica, através da qual seria possível uma expansão da consciência, o condiciona dentro da promessa do happy end.

Segundo Morin, happy end seria a felicidade do herói simpático, o final feliz quando tudo indicava que ele não se sairia bem, que seria conduzido ao fracasso, ou a uma saída trágica. ${ }^{19} \mathrm{O}$ embate dramático desse herói, em vez de ser solucionado por meio de uma longa prova ou até mesmo da morte, se resolve no happy end, em que não há reparação ou renascimento, mas irrupção de uma felicidade que se torna o núcleo afetivo do novo imaginário. É no emaranhado desse discurso imediatista de felicidade outorgado pela indústria cultural que nasceram os super-heróis da atualidade. Apesar do contexto histórico que favoreceu e até exigiu sua ascensão, super-heróis são produtos culturais da sociedade industrial. Dessa maneira, estarão sempre sujeitos a transformações de acordo com as necessidades tanto da história como da indústria do consumo.
19. MORIN Cultura de massas no século XX: neurose, p. 176. 
20. Sandman, também conhecido no Brasil como João-Pestana, é um personagem originário do ser responsável por trazer os sonhos para as crianças enquanto dormem.

21. CAMPBELL. O Herói de Mil Faces, p. 16

\section{CONSIDERAÇÕES FINAIS}

A narrativa mitológica esteve por muitos anos em posição de dar ao ser humano as direções do mundo, explicações básicas da vida capazes de orientar o sujeito na aventura maravilhosa e fascinante que é estar vivo. Podemos perceber que o super-herói surge na indústria para salvar o homem moderno de sua vida regada de incertezas, que assombram a sociedade como um todo. Surge como fonte de inspiração, ligação e válvula de escape do mundo real.

O mito transformou-se de tal maneira ao se encaixar na sociedade industrial que agora nos ensina quase o oposto do que aprendemos com o herói antigo. Encoberto por um discurso mágico de felicidade que é incapaz de suprir eficientemente os desejos da alma humana, nos coloca em lugar de coadjuvantes e não mais de protagonistas. A promessa de felicidade imediatista que impele o homem a viver sob o princípio do prazer, onde a dor não deve ou não precisa ser vivida, cobre os nossos olhos com a areia mágica de Sandman ${ }^{20}$ longe de nos envolver na verdadeira batalha onírica. Agora o herói começa a ser usado como desculpa e fator de negação. De acordo com Campbell, ${ }^{21}$ todos precisamos compreender a morte e enfrentar a morte. O herói mitológico desenvolvia, enquanto arquétipo, o papel de espelho, demonstrando em sua jornada o caminho para a autorrealização do sujeito, o qual, para alcançar seu objetivo, morria simbolicamente renascendo em sabedoria e maturidade.
Ao estabelecer a "ditadura do happy end", em que as coisas contribuem para um fim onde o homem não mais precise sentir dor, nascem os Super-Homens. Contrariando o caminho do herói mitológico, a existência do super-herói é justificada na ideia de que ele está aqui para resolver todos os nossos problemas. Se antes os heróis nos davam um caminho a se seguir e um modelo para se inspirar, hoje, os super-heróis dão-nos suas vidas, vidas já vividas, sem custar-nos qualquer exigência ou comprometimento. Super-Heróis vivem unicamente para atender aos desejos de uma sociedade que não aceita outra coisa além de um final feliz. Desse modo, surge uma desorganização espacial em que aquele que seria capaz de suportar o peso e as amarrações geradas entre o sujeito e a sociedade e que possui a capacidade de gerar o mito está ausente ou é fragmentado.

Ao experienciar o herói que existe e está ao alcance de qualquer um de nós, estamos tomando as rédeas dos acontecimentos em nossas vidas e criando a possibilidade inovadora que é inata ao ser humano. Quando essa experiência é estagnada pela promessa de que não precisamos mais experimentar a dor da batalha heroica, pois existe alguém que o fará em seu lugar, elimina-se a possibilidade de crescimento e mutação, e estagna-se o movimento básico necessário à vida. Deixar de acreditar nos mitos e perder a sensibilidade simbólica foi o que delegou o homem ao lugar de adorador de objetos. Apreciar os super-heróis enquanto modelos de

EM TESE

BELO HORIZONTE

v. 22

N. 2

MAIO-AGO. 2016

MULATO; VELÁZOUEZ. Esse tal de final feliz

P. $175-186$ 
projeção ou identificação é uma dinâmica inconsciente que guarda em seu processo uma centelha perigosa.

Super-Homens, como o governo ou líderes religiosos, por vezes têm assumido o papel de guardiões de nossos destinos, mas, no fundo, sabemos que a jornada da autorrealização é uma caminhada que precisamos fazer sozinhos. É bom lembrar que os verdadeiros heróis das tramas em que estamos envolvidos somos nós mesmos. Como diriam os Jedis nos famosos filmes da franquia Star Wars, "que a força esteja com você”. E ela, de fato, está.

\section{REFERÊNCIAS}

ADORNO, Theodor; HORKHEIMER, Max. Dialética do

Esclarecimento. São Paulo: Zahar, 1996.

BAUDRILLARD, Jean. A sociedade de consumo. Rio de Janeiro: Elfos Editora, 1995.

BENJAMIN, Walter. Textos escolhidos. São Paulo: Abril Cultural, 1983

CAMPBELL, Joseph. 0 Herói de Mil Faces. São Paulo: Cultrix Pensamento, 1995.

ECO, Umberto. Apocalípticos e integrados. São Paulo: Perspectiva, 1979.

ELIADE, Mircea. O sagrado e o profano. São Paulo: Martins Fontes, 1995.
JUNG, Carl Gustav et al. O homem e seus símbolos. Rio de Janeiro: Nova Fronteira, 2008.

JUNG, Carl Gustav. Tipos psicológicos. Petrópolis: Vozes, 2009

JUNG, Carl Gustav; KERÉNYI, Karl. A criança divina: uma introdução à essência da mitologia. Petrópolis: Vozes, 2011.

MORIN, Edgar. Cultura de massas no século XX: neurose. Rio de Janeiro: Forense Universitária, 1997.

MORRISON, Grant. Superdeuses. São Paulo: Seoman, 2012.

MULLER, Lutz. O Herói: Todos nascemos para ser heróis. São Paulo: Cultrix, 1992 